\title{
Relating Normal Pulse Rate with Dandruff in Hair Cells
}

\author{
Muhammad Imran Qadir, Usama Razzaq* \\ Institute of Molecular Biology and Biotechnology, Bahauddin Zakariya University, Multan, Pakistan. \\ *Corresponding Author: Usama Razzaq, Institute of Molecular Biology and Biotechnology, Bahauddin \\ Zakariya University, Multan, Pakistan.
}

\begin{abstract}
The Objective of this Article was to associate Normal pulse rate with dandruff in hair cells. Pulse rate is the measurement of a person's heart beats per minute. 60 to 100 beats per minute are considered normal at resting phase. Dandruff is a ceaseless condition of scalp due to dryness of skin, over-production of sebum and not shampooing week after week. This article also discusses about Dandruff, its causes and its treatment. Total of 200 students participated in this activity. A Questionnaire based study was prepared to relate normal Pulse rate and Dandruff. Dandruff has no scientific relation with pulse rate.
\end{abstract}

Keywords: Pulse rate, Tachycardia, Bradycardia, Dandruff, Anti-Dandruff shampoos.

\section{INTRODUCTION}

Pulse rate is the calculation of a person's heart beats per minute. 60 to 100 beats per minute are considered as normal pulse rates. Normal resting pulse rates in babies of age less than 1 year is 100$160 \mathrm{bpm}$, babies of age from 1 to 10 year have $70-120 \mathrm{bpm}$ and adults have 60-100 bpm. The prominent places to find a pulse is at wrist, at top of foot, at side of neck and inside of the elbow. Radial artery at Wrist position, Dorsalis pedis artery at the foot position, Common Carotid artery at the side of neck and Brachial artery inside of the elbow are major pulse positions for pulse rate measurement. To count your pulse rate, put your thumb over pulse and count beats per minute by using stopwatch. The main purpose to check your pulse is to determine whether your pulse rate is within normal range. Pulse or heart rate depends on factors such as body position, age, medication usage, stress and emotions. Body position includes sitting, running or doing exercise. Hearts beats is more while doing exercise. People doing physical activity or athlete have usually lower heart rates. Heart beats also depend on age factor. Old people have more heart beats per minute. Medication usage is also a factor, usage of beta-blockers slows down pulse rate, while taking thyroid medication raise pulse rate. Heart beats are more in stress or depression stage than in normal case. While Pulse rate is more at excited stage than in normal position. Pulse rate below $60 \mathrm{bpm}$ with exception in athletes or above 100 at rest is considered as threat. The pulse rate below $60 \mathrm{bpm}$ is called Bradycardia. Hypotension, blurred vision, cool and dizziness are its common symptoms. While pulse exceeding $100 \mathrm{bpm}$ is called Tachycardia. Headache, weakness, anxiety are its symptoms. (1)

Dandruff is a ceaseless condition of hair skin cells due to overproduction of a secretion Sebum that lubricates hair and skin cells. It is inflammatory condition of scalp. Dandruff is common in adults, it starts from adulthood and lasts if not cured. Dandruff is caused due to dust, dry scalp, not shampooing week after week, over-use of hair gels and dyes, taking stress weakens immune system, alkaline soap usage and more secretion of sebaceous glands. The main cause is the over- growth of yeast like fungus Malassezia that grows over the hair skin, skin cells grow more and extra cell become dead fall off as flaky white dots regarded as dandruff. Symptoms of dandruff are itchiness, flaking of skin cells as white dots, redness of the skin surface, and if not treated then hairs fall off from their roots. Mild condition of dandruff is not threatening but severe condition requires medical attention. Dandruff is temporarily treated through anti-dandruff shampoos and through home remedies. Anti-dandruff shampoos are Head and Shoulder, zincon shampoo and Selsun Blue. Dandruff is permanently treated through the use of shampoos that have Zinc pyrithione, Selenium sulphide and coal tar as main ingredients. While home remedies involve use of Lemon+ Coconut oil mixture and then apply on hair reduces dandruff because coconut oil act as a agent to improve the skin hydration while lemon has antifungal properties, its acidic nature balances $\mathrm{pH}$ of scalp. Olive oil also used on hairs being 
effective against dandruff because of its anti-viral and anti-inflammatory properties, Apple cider usage balance the oil production of scalp also it has anti-inflammatory properties and Aloe Vera has anti-fungal and anti-bacterial properties whose usage repairs dead skin cells and improves hair health. (2)

The Objective of this Article was to study Normal pulse rate with respect to dandruff in hair cells.

\section{MATERIALS AND METHODS}

For measurement of pulse rate, firstly washed your hands then checked your pulse on wrist position by putting thumb on it. Then check pulse rate till 15 seconds by using stopwatch. Then multiply the reading obtained by $4 \mathrm{X}$. For accurate reading, do these procedures for second time then take their average.

\subsection{Statistical Analysis}

Statistical analysis of this study was performed by the use of Microsoft Excel Stat software. (3)

\section{RESULTS AND DISCUSSION}

Table1. Relation of Normal pulse rate (Mean $\pm S D)$ with Dandruff.

\begin{tabular}{|c|c|}
\hline (Connection of pulse rate with Dandruff threat). & (Connection of pulse rate with no Dandruff signs). \\
\hline $79.02 \pm 13.13$ ( Mean \pm SD) & $81.1 \pm 12.28$ ( Mean \pm SD) \\
\hline
\end{tabular}

p>0.05, data is non-significant.

\section{CONCLUSION}

Dandruff has no scientific relation with pulse rate.

\section{REFERENCES}

[1] Qadir MI, Malik SA (2010) Comparison of alterations in red blood cell count and alterations in hemoglobin concentration in patients suffering from rectal carcinoma undergoing 5-fluorouracil and folic acid therapy. Pharmacology online, Nl 3: 240-243.

[2] Qadir MI, Noor A (2018) Anemias. Rare \& Uncommon Diseases. Cambridge Scholars Publishing. Newcastle, England. ISBN: 978-1-5275-1807-0.

[3] Qadir MI, Javid A (2018) Awareness about Crohn's Disease in biotechnology students. GloAdv Res J Med Medical Sci, 7(3): 062-064.

[4] Qadir MI, Saleem A (2018) Awareness about ischemic heart disease in university biotechnology students. GloAdv Res J Med Medical Sci, 7(3): 059-061.

[5] Qadir MI, Ishfaq S (2018) Awareness about hypertension in biology students. Int J Mod Pharma Res, 7(2): 08-10.

[6] Qadir MI, Mehwish (2018) Awareness about psoriasis disease. Int J Mod Pharma Res, 7(2): 17-18.

[7] Qadir MI, Shahzad R (2018) Awareness about obesity in postgraduate students of biotechnology. Int J Mod Pharma Res, 7(2): 14-16.

[8] Qadir MI, Rizvi M (2018) Awareness about thalassemia in post graduate students. MOJ Lymphology\&Phlebology, 2(1): 14-16.

[9] Qadir MI, Ghalia BA (2018) Awareness survey about colorectal cancer in students of M. Phil Biotechnology at BahauddinZakariya University, Multan, Pakistan. Nov Appro in Can Study, 1(3): NACS.000514.2018.

[10] Qadir MI, Saba G (2018) Awareness about intestinal cancer in university student. Nov Appro in Can Study, 1(3): NACS.000515.2018.

[11] Saint-Leger D. Dandruff (pityriasis capitis simplex): of yeasts and men. The science of hair care. 2005 Feb 28:609-31.

[12] Draelos ZD. The biology of hair care. Dermatologic clinics. 2000 Oct 1; 18(4):651-8.

Citation: Muhammad Imran Qadir, Usama Razzaq, "Relating Normal Pulse Rate with Dandruff in Hair Cells" International Journal of Research Studies In Biosciences (Ijrsb), Vol. 7, no. 8, pp. 24-25, 2019. http://Dx.Doi.org/10.20431/2349-0365.0708005

Copyright: (C) 2019 Authors. This is an open-access article distributed under the terms of the Creative Commons Attribution License, which permits unrestricted use, distribution, and reproduction in any medium, provided the original author and source are credited. 